\title{
Assessing ecological response of the Big Pine Creek watershed to climate change using time series analysis of Landsat surface reflectance data over a 28 -year period
}

\author{
P. S. Sawyer \& H. Stephen \\ School of Environmental and Public Affairs, \\ University of Nevada Las Vegas, USA
}

\begin{abstract}
This paper presents a time series study of an alpine ecosystem in the Big Pine Creek watershed in California's Eastern Sierra Nevada Mountain's. Raw Landsat data covering the years 1984 through 2011 is converted to observed surface reflectance and analysed for trends. Analysis of environmental data indicates a definite warming trend while observed surface reflectance shows a general decline for the study area over this time period. While declining reflectance in the visible bands suggests an increase in surface vegetative cover, the fact that the IR band also shows declines suggests a potential change in vegetative composition towards species with less structural complexity. This study provides a useful insight into the ecological response of the Big Pine Creek watershed.

Keywords: Landsat, remote sensing, alpine watershed, climate change, time series Mann-Kendall trend analysis.
\end{abstract}

\section{Introduction}

A significant portion of fresh water supplies are tied to glacial and alpine ecosystems that are vulnerable to variations in the earth's climate (Barnett et al. [1]). Since these regions exist at the boundaries of climate zones such as the higher and lower latitudes and at high elevations where several ecotones may occur in a small geographic area they will witness the first signs of climate change impact on the environment. Biomes that populate these habitats are highly susceptible to changes in environmental conditions (Lindner et al. [2]). As 
the environmental characteristics of individual ecosystems change, the physiological processes dependent on those environmental parameters also change, resulting in variations in the spectral response of both soils and vegetation.

We hypothesize that higher temperatures combined with increased atmospheric $\mathrm{CO}_{2}$ levels will increase photosynthesis resulting in increased biomass; provided other essential resources are not limited (Skre and Naess [3]). The spectral characteristics of vegetation enable us to analyze ecological properties using remote sensing instruments such as the Landsat Thematic Mapper (TM). Vegetation has characteristic spectral responses that correlate to variation in vegetative cover and plant health such as low red reflectance due to chlorophyll absorption and high near-IR reflectance due to the reflectance of the internal structures of the canopy (Wessman [4]). Soil also demonstrates unique spectral characteristics depending on properties such as its moisture, organic matter content and texture (Jackson et al. [5]). Lower soil moisture content, a possible indicator of water stress in vegetation, will cause higher surface reflectance in the mid-IR region that can be detected using Landsat data (Musick and Pelletier [6]).

In this paper we examine an alpine watershed using time series analysis of Landsat imagery. The Landsat imagery is processed to derive observed surface reflectance values. We then apply a statistical approach to determine the presence of any trends in the data that would validate the hypothesis of increased vegetation resulting from higher temperature and atmospheric $\mathrm{CO}_{2}$ levels. We present this information by first describing the study area and the data used in the analysis, we then discuss the research approach and methods used to collect and process the data, followed by our results and conclusions.

\section{Study area and data}

This section describes the study area and the data used in the analysis.

\subsection{Study area description}

Figure 1 below shows the Big Pine Creek watershed located in California's Eastern Sierra Mountains. Big Pine Creek is a major tributary to the Owens River which is a significant source of fresh water for Los Angeles. The Owens River valley straddles the Great Basin and Mojave deserts with vegetation consisting primarily of pine forests at higher elevations and xeric species at lower elevations. Areas bordering streams and the Owens River are primarily grass dominated meadows (Elmore et al. [7]). Elevation within the watershed increases from East to West with the higher regions dominated by barren rock and woodlands with the lower regions dominated by mixed desert shrubs. 


\section{Big Pine Creek Watershed on the Eastern Slopes of California's Eastern Sierra Mountains}

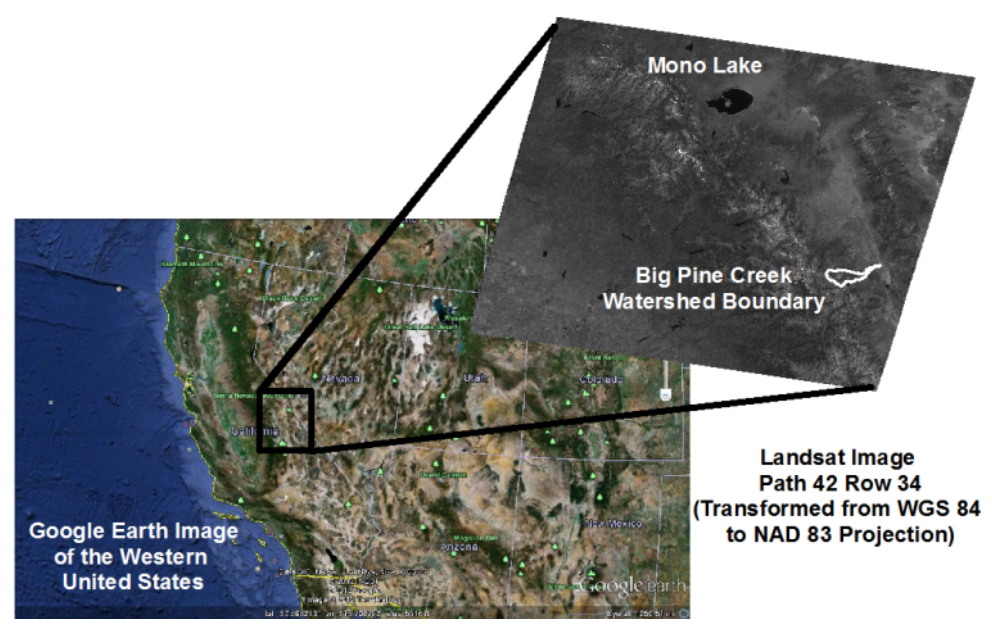

Figure 1: $\quad$ Study area location showing the boundary of the Big Pine Creek watershed.

\subsection{Data}

The data in this study includes Landsat spectral reflectance data and PRISM generated meteorological data as is described below.

\subsubsection{Spectral data}

The Landsat 5 TM imagery used in this analysis was acquired for 28 dates in the July time frame from 1984 (year of launch) through 2011 (year turned off). For this analysis, only Landsat 5 TM imagery was used to ensure consistency of the data. Most of the imagery used in this analysis is from Path 42, Row 34 with four of the images from Path 41, Row 34. Both image ID ground swaths cover the entire study area. The imagery used in this study was obtained from the EarthExplorer web site operated by the United States Geological Survey (USGS) http://earthexplorer.usgs.gov/ [8]. The TM sensor collects data in six reflectance bands in the visible, near infrared and mid infrared regions and one thermal band. This information and additional detailed specifications on the TM sensor is found on the Landsat website, http://landsat.gsfc.nasa.gov/about/tm.html [9].

\subsubsection{Meteorological data}

Meteorological data examined in this study is obtained from the University of Oregon's Parameter-elevation Regressions on Independent Slopes Model (PRISM) web site http://www.prism.oregonstate.edu/ [10]. According to this website, PRISM data are modeled estimates based on point data and a digital elevation model and is available for the entire continental US at $4 \mathrm{~km}$ resolution. 
All 30 sample sites in this study fall within 5 PRISM grid cells as shown in Figure 2. Figure 2 also shows the most abundant land cover classes present in the watershed in addition to the surface water bodies present in the upper elevations. There are 34 land cover classifications with the ten most abundant covering 93\% of the total surface area.

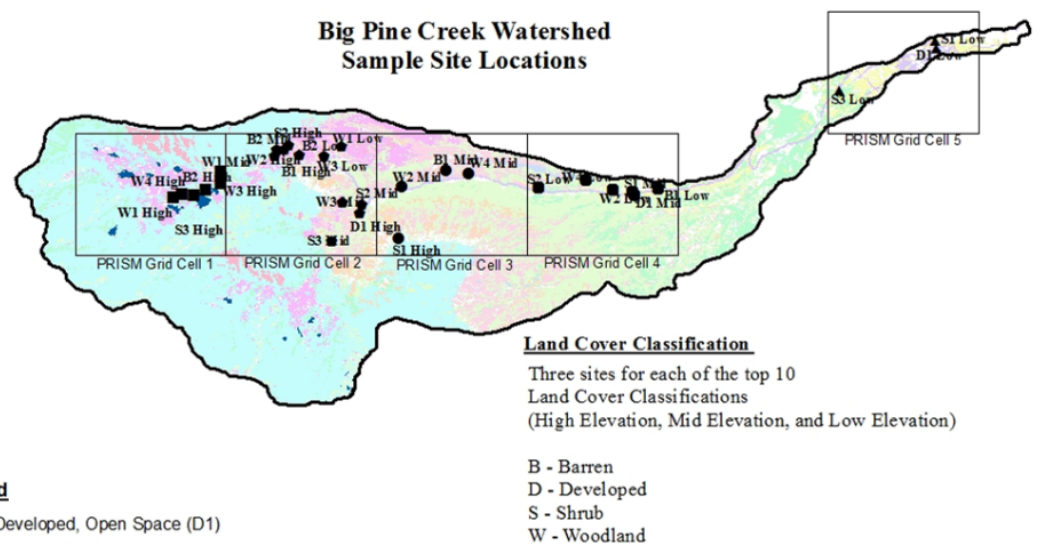

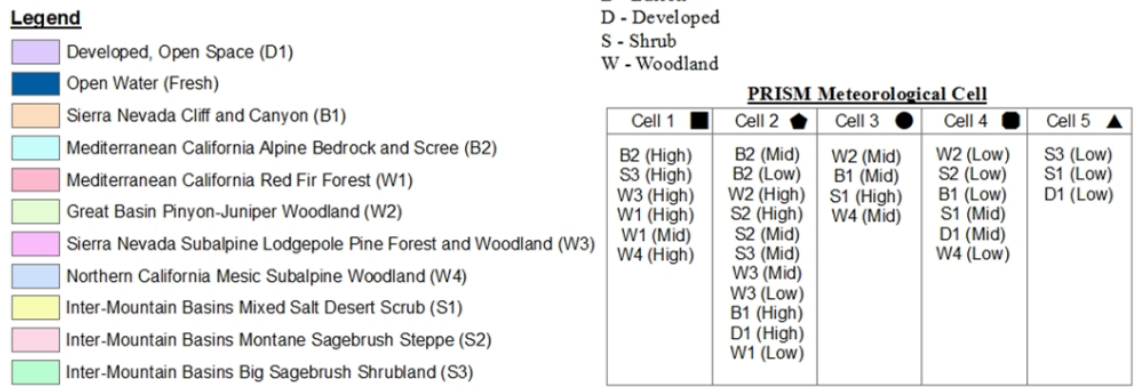

Figure 2: Land cover classification of the study area and location of sample sites and the PRISM meteorological cells.

\section{Research approach and methods}

This section contains a description of our research approach and the methodology we used to collect and process the data.

\subsection{Research approach}

This study examines how the spectral response of the watershed has changed over the last 28 years. The goal is to determine if there are any significant trends in the data that would suggest climate change impacts to the vegetation in the study area have already occurred. Since the period of maximum leaf area index generally occurs in the mid-June to mid-August time frame (Gond et al. [11]), only imagery in the July time frame was considered for this analysis in order to minimize the impacts of the phenological cycle on the reflectance data. In order to ensure a representative sample of numerous vegetative species present in the 
watershed, three sample sites at different elevations, from each of the ten most abundant land cover classifications are used for a total of 30 sample sites. Landsat data for each site is processed and converted to observed surface reflectance. A time series trend analysis is then performed to identify any statistically significant trends in the data that would suggest changes in the amount, health, or composition of vegetation in the watershed.

\subsection{Research methods}

The research methodology consists of data collection; data processing; and statistical analysis. Each step is described below.

\subsubsection{Data collection}

The data analyzed in this study includes the spectral response measured by the satellite in each of the six reflective bands of the TM sensor. Geometric pixel registration errors are generally below 0.5 pixels (Schueler and Salomonson [12]). To account for these errors, the pixel values for each sample site were resampled by averaging the eight adjacent pixel values along with the sample site pixel value. In order to perform a temporal study comparing the physiological changes over time at each of the sample sites, the raw Landsat data was converted to observed surface reflectance values for each year of the study period. This process involves first converting the digital numbers to at-sensor radiance values, then transforming the radiance to top of atmosphere reflectance and finally, performing an atmospheric correction to obtain observed surface reflectance (Chavez [13]).

\subsubsection{Data processing}

The raw Landsat imagery was processed to observed surface reflectance by first converting the digital numbers to at sensor radiance values by removing the gain and offset caused by the sensors themselves Chavez [13]. Following the methods developed by Chander and Markham [14], the spectral radiance at the sensor $\left(L_{\lambda}\right)$ is determined using

$$
L_{\lambda}=\left(\frac{L_{M a x}-L_{M i n}}{Q_{C a l \max }}\right) \cdot Q_{C a l}+L_{M i n},
$$

and top of atmosphere reflectance $(\rho)$ is calculated using

$$
\rho_{p}=\frac{\pi \cdot L_{\lambda} \cdot d^{2}}{E S U N_{\lambda} \cdot \operatorname{Cos} \theta_{s}}
$$

where $Q_{c a l}$ is the calibrated digital number, $L_{\lambda}$ is the spectral radiance at the sensor's aperture, in $\mathrm{W} / \mathrm{m}^{2} \bullet \mathrm{sr} \bullet \mu \mathrm{m}, L_{\text {Max }} \lambda$ is the spectral radiance scaled to $Q_{C a l}$ max, $L_{\text {Min } \lambda}$ is the spectral radiance scaled to $Q_{\text {Cal min, }}, \rho_{P}$ is the unitless planetary reflectance, $L_{\lambda}$ is the spectral radiance at the sensor's aperture, $d$ is the earth sun 
distance in astronomical units, $E S U N_{\lambda}$ is the mean solar exoatmospheric irradiances, $\theta_{s}$ is the solar zenith angle in degrees (Chander and Markham [14]).

Observed surface reflectance is then determined using the "Dark Object Subtraction" (DOS) method developed by Chavez [13] which is based on the assumption that radiance seen at the satellite for "dark" pixels (i.e. deep water) result purely from atmospheric path radiance. This allows us to process imagery where atmospheric column data is not available (generally pre-2000). For this analysis DOS is performed using the $\operatorname{Cos} \theta$ or "COST" method developed by Chavez [13]. First the minimum radiance is determined using

$$
L_{\lambda, \text { min }}=L_{\text {Min } \lambda}+\left(\frac{L_{M a x \lambda}-L_{M i n}}{Q_{\text {Cal max }}}\right),
$$

the theoretical radiance of a dark object (assuming a 1\% reflectance) is then calculated using

$$
L_{\lambda, 1 \%}=\frac{0.01 \cdot d^{2} \cdot \operatorname{Cos}^{2} \theta}{\pi \cdot E S U N_{\lambda}} .
$$

A haze correction factor is then calculated using

$$
L_{\lambda, \text { haze }}=L_{\text {Min } \lambda}-L_{\lambda, 1 \%} .
$$

And finally, the corrected surface reflectance value is determined using

$$
\rho_{P}=\frac{\pi \cdot d^{2} \cdot\left(L_{\lambda}-L_{\lambda, \text { haze }}\right)}{\operatorname{ESUN}_{\lambda} \cdot \operatorname{Cos}^{2} \theta} .
$$

\subsubsection{Statistical analysis}

Statistical analysis is used to test our hypothesis that recent climate change has altered the vegetative composition of the study area. The non-parametric MannKendall (MK) trend test is used to establish the presence of a trend in the surface reflectance observations and meteorological data over the last 28 years. This analysis looks at the sums of the signs of the differences between the data sets and calculates an "S" statistic with the following properties: for $\mathrm{S}<0$ (values are decreasing over time); for $S>0$ (values are increasing over time). The magnitude of the S-statistic is a measure of the strength of the trend. S values of + or -100 indicate a statistically significant trend with a $p$ value of $<0.05$. This means the null hypothesis of no-trend in the data can be discarded with the risk of committing a Type II (rejection of a true null or $H_{0}$ ) error at less than $0.01 \%$. The MK S-statistic is calculated using

$$
S=\sum_{i=1}^{n-1} \sum_{j=i+1}^{n} \operatorname{sign}\left(x_{j}-x_{i}\right),
$$


where $n$ is the number of observations and $x_{i}(i=1 \ldots n)$ are the independent observations (De Beurs and Henebry [15]). These calculations are carried out in Excel using the XLSTAT add-in statistical package. This program generates the S statistic as well as the probability $(p)$ value which is used to quantify the statistical significance of the trend.

\section{Results and discussion}

This section presents the results obtained from our analysis of the spectral response and meteorological data. Correlations between the spectral response and meteorological data as well as confidence levels are briefly discussed.

\subsection{Spectral data}

The left side of Figure 3 below shows the observed surface reflectance for each of the six Landsat TM reflectance bands over the 28 year study period averaged for all 30 sample sites. The right side of Figure 3 shows how each of these spectral bands has trended for each of the four primary land cover types in the study area.

The declines in the blue (band 1), green (band 2), and red (band 3) regions of the spectrum all suggest increased absorption from increased chlorophyll. With the larger reductions in the blue and red regions and less reduction in the green region matching what would be expected with increased vegetative ground cover due to the strong blue and red chlorophyll absorption features in vegetation. However, since the near-IR (band 4) region also shows significant decline, the increase in vegetative surface cover, suggested by the decrease in the visible region, is structurally less dense. Two possible explanations are that there is simply more new growth which has yet to develop the structural complexity of existing vegetation, or the new growth is composed of different species with less complexity.
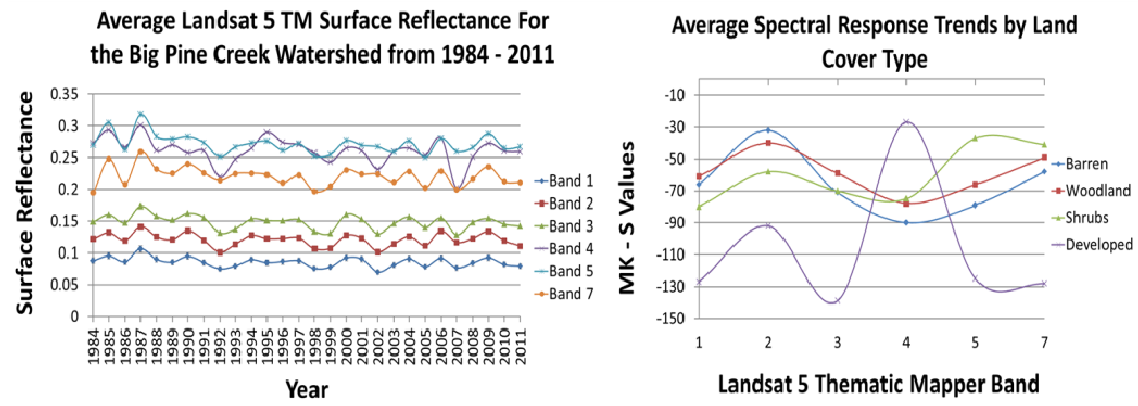

Figure 3: $\quad$ Landsat 5 TM observed surface reflectance averaged over all 30 sample sites and trends in the observed surface reflectance of each Landsat 5 TM reflectance band for the four land classes (Barren, Woodland, shrubs, and developed). 
While the barren, woodland, and shrub land types all show a consistent pattern with smaller declines in the green (band 2) region and larger declines in the near-IR (band 4), the developed areas show a different pattern across the spectrum with significant declines in the red (band 3) and mid-IR (bands 5 and 7) while showing much lower declines in the near-IR (band 4).
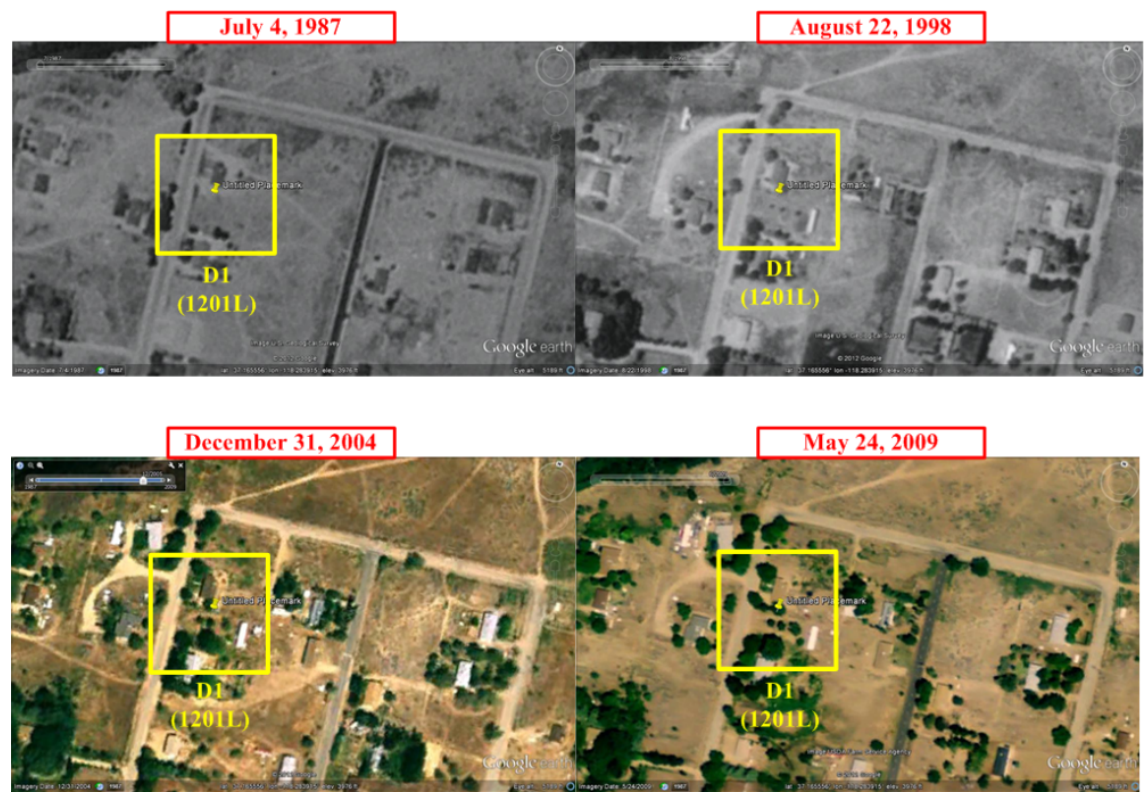

Figure 4: Historical Google earth imagery of one of the developed land class sites showing increases in trees and shrubs over the study period.

This difference in the developed areas can be explained by the significant increase in trees and shrubs at one of the developed area sample sites, validated by historical satellite imagery as shown in Figure 4 above. The increase in vegetative cover as well as structural complexity results in lower visible band reflectance and increased near-IR reflectance.

Table 1 shows the results of the trend tests for each of the Landsat 5 TM bands. For the average of band 1 data, the $S$ value of -78 indicates values are declining over time. The $p$-value of 0.130 indicates that the risk of rejecting the null hypothesis of no trend is only $12.95 \%$. Similarly, for band 2 the risk of rejecting the no trend null hypothesis is $42.2 \%$; band 3 it is $6.61 \%$; band 4 it is $5.51 \%$; band 5 it is $11.5 \%$; and for band 7 the risk is $17.49 \%$.

Figure 5 shows the observed surface reflectance trends for each of the 30 sample sites arranged by their elevation. The data shows that of the 180 observed surface reflectance data sets (30 sites x 6 reflectance bands), 153 have negative S values indicating lower surface reflectance over time, while 28 data sets are positive, indicating increasing surface reflectance over the time period of the study (1984-2011). Looking more closely at the strength of the trends, 58 of the 
data sets (32\%) show a statistically significant negative trend ( $<<0.05), 24$ data sets $(13 \%)$ demonstrate likely negative trend $(0.1<\mathrm{p}<0.05)$ and 3 data sets show likely positive trends $(0.1<\mathrm{p}<0.05)$.

Table 1: $\quad$ Observed surface reflectance trend statistics.

\begin{tabular}{||c|c|c|c|c|c||}
\hline \hline Band & $\begin{array}{c}\text { MK-S } \\
\text { Value }\end{array}$ & $p$ & $\bar{x}$ & $\sigma$ & $C I$ \\
\hline $1(0.45-0.52 \mu \mathrm{m})$ & -78 & 0.130 & 0.085425 & 0.007659 & \pm 0.003024 \\
\hline $2(0.52-0.60 \mu \mathrm{m})$ & -42 & 0.422 & 0.120744 & 0.009910 & \pm 0.003913 \\
\hline $3(0.63-0.69 \mu \mathrm{m})$ & -94 & 0.066 & 0.198404 & 0.010816 & \pm 0.004271 \\
\hline $4(0.76-0.90 \mu \mathrm{m})$ & -98 & 0.055 & 0.260976 & 0.020168 & \pm 0.007964 \\
\hline $5(1.55-1.75 \mu \mathrm{m})$ & -82 & 0.110 & 0.271658 & 0.014862 & \pm 0.005869 \\
\hline $7(2.08-2.35 \mu \mathrm{m})$ & -70 & 0.175 & 0.220562 & 0.014828 & \pm 0.005855 \\
\hline
\end{tabular}

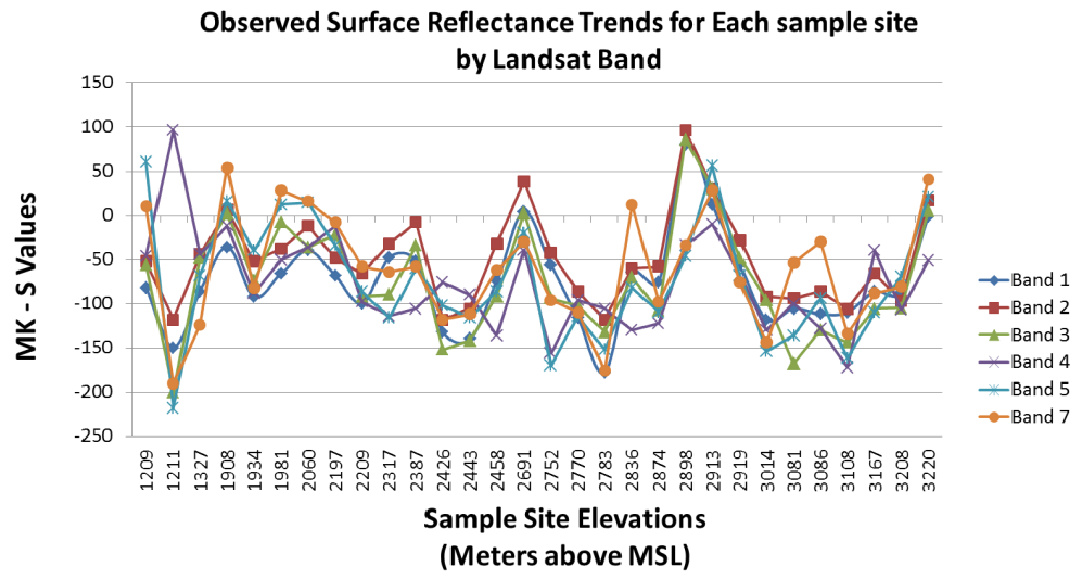

Figure 5: $\quad$ Surface reflectance trends for each of the 30 sample sites for all six Landsat TM reflective bands. Sample sites are identified by their elevation in meters above mean sea level.

\subsection{Meteorological data}

The meteorological data analyzed in this study include the monthly average precipitation (PPT), monthly average maximum temperature $\left(\mathrm{T}_{\mathrm{MAX}}\right)$, the monthly average minimum temperature $\left(\mathrm{T}_{\mathrm{MIN}}\right)$ and the monthly mean dew point temperature $\left(\mathrm{T}_{\mathrm{DEW}}\right)$.

The most striking observation is the statistically significant positive trends in both the monthly average maximum temperature $\left(\mathrm{T}_{\mathrm{MAX}}\right)$ and monthly average minimum temperature $\left(\mathrm{T}_{\mathrm{MIN}}\right)$ over the time period of the study as shown in Figure 6 below. Of the 60 data sets analyzed, $65 \%$ of the $\mathrm{T}_{\mathrm{MAX}}$ and $85 \%$ of the $\mathrm{T}_{\text {MIN }}$ values show statistically significant positive trends. For the precipitation data, $50 \%$ show negative trends and $50 \%$ show positive trends. Only $7 \%$ of the 
precipitation data sets show statistically significant trends (negative). The dew point temperatures $\left(\mathrm{T}_{\mathrm{DEW}}\right)$, which are an indication of atmospheric moisture content show a preponderance of negative $S$ values (85\%) indicating a reduction in humidity levels. There are statistically significant declines in $\mathrm{T}_{\mathrm{DEW}}$ in the months of August and September.
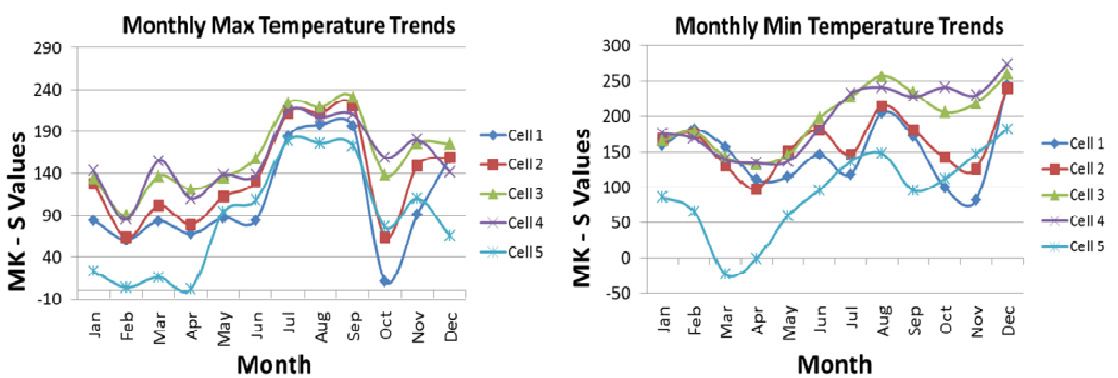

Figure 6: Monthly temperature trends for the 1994 through 2011 time period.

\subsection{Data correlations}

A comparison of the maximum, minimum, and dew point temperature climatic variables, and precipitation versus the surface reflectance values was performed using Kendall's Tau $(\tau)$ non-parametric rank correlation test. This test determines the strength of the link between two variables. For $\tau=1$; the two variables are in perfect agreement. If $\tau=-1$; the two variables are in perfect disagreement (inversely correlated). And if $\tau=0$, the variables are completely independent. Results of this test show most of the Landsat 5 TM bands have a small negative correlation with $\mathrm{T}_{\mathrm{MAX}}$ and $\mathrm{T}_{\mathrm{MIN}}$.

Statistically significant correlations with reflectance data are found in approximately $11 \%$ of the data sets including PRISM cell 3 for $\mathrm{T}_{\text {MAX }}$ in the nearIR band $4(\tau=-0.344, p=0.011)$; and $\mathrm{T}_{\mathrm{MIN}}$ in the near-IR band $4(\tau=-0.354, p=$ 0.009 ) and mid-IR band $7(\tau=-0.270, p=0.46)$. Dew point temperatures show statistically significant negative correlations in PRISM cell 4 for the mid-IR band $5(\tau=-0.275, p=0.042)$; and mid-IR band $7(\tau=-0.365, p=0.004)$ and in PRISM cell 5 for the red band 3 ( $\tau=-0.275, p=0.042$ ); the mid-IR band 5 ( $\tau=$ $0.280, p=0.038)$; and mid-IR band $7(\tau=-0.307, p=0.023)$. Precipitation shows statistically significant negative correlations in PRISM cell 5 for the blue band 1 ( $\tau=-0.347, p=0.01)$; the green band $2(\tau=-0.283, p=0.036)$; the red band 3 ( $\tau=-0.310, p=0.022)$; the mid-IR band $5(\tau=-0.474, p=0.0004)$; and mid-IR band $7(\tau=-0.453, p=0.001)$.

\subsection{Confidence levels}

Multitemporal satellite imagery is impacted by several factors including changes in sensor response, sensor stability, atmospheric effects, and illumination effects (Vicente-Serrano et al. [16]). Radiometric uncertainty for the TM data is 
approximately 5\% (Chander et al. [17]). The confidence levels in the data are shown in Table 1 for the spectral reflectance data for each of the six reflective Landsat 5 TM bands averaged over all 30 sample sites.

\section{Summary and conclusions}

This study examined the changes in observed surface reflectance values at 30 sample sites in the Big Pine Creek watershed over a 28 year time span from 1984 through 2011. While reduced surface reflectance in the visible bands suggests increased vegetation cover, the fact that the near-IR reflectance is also decreasing suggests that any additional vegetative cover is structurally less dense. At one sample site, the near-IR is higher while the visible reflectance is lower indicating an increase in vegetative cover and density. This result is validated by historical satellite imagery showing increased tree and shrub cover over the last 28 years.

Average monthly minimum and maximum temperatures show statistically significant upward trends. Increased temperatures combined with the increasing levels of atmospheric carbon dioxide $\left(\mathrm{CO}_{2}\right)$ suggest potential increases in photosynthetic activity as long as that process is not limited by other factors such as lack of water availability (Skre and Naess [3]). In areas without water or other nutrient resource limitations, these conditions are conducive for increased biomass resulting in stronger absorption in the visible region of the spectrum. The statistically significant declines in late summer dew point temperatures suggest a moisture deficit may be developing during the least rainy months of the year. However, while the near-IR reflectance would be expected to decline in moisture stressed vegetation, the mid-IR (band 5) is expected to increase (Todd and Hoffer [18]). The data in this analysis do not reflect increased mid-IR reflectance. The reduced mid-IR values we observe are actually an indicator of increased biomass since the mid-IR is highly reflective in barren areas and reduced in vegetated areas. All of these observations suggest an increase of ecosystem biomass with reduced structural complexity.

\section{References}

[1] Barnett, T.P., J.C. Adam, and D.P. Lettenmaier, Potential impacts of a warming climate on water availability in snow-dominated regions. Nature, Reviews 438 (17), pp. 303-309, 2005.

[2] Linder, M., M. Maroschek, S. Netherer, A. Kremer, A. Barbati, J. GarciaGonzalo, R. Seidl, S. Delzon, P. Corona, M. Kolstrom, M.J. Lexer, and M. Marchetti, Climate change impacts, adaptive capacity, and vulnerability of European forest ecosystems. Forest Ecology and Management, 259, pp. 698-709, 2010.

[3] Skre, O. and M. Naess, $\mathrm{CO}_{2}$ and winter temperature effects on white birch. Chemosphere: Global Change Science, 1, pp. 469-483, 1999.

[4] Wessman, C.A., Imaging Spectrometry for Remote Sensing of Ecosystem Processes. Advances in Space Research, 12 (7), pp. 361-368, 1992. 
[5] Jackson, R.D., P.J. Pinter, Jr., R.J. Reginato, and S.B. Idso, Detection and Evaluation of Plant Stresses for Crop Management Decisions. IEEE Transactions on Geoscience and Remote Sensing, GE-24 (1), pp. 99-106, 1986.

[6] Musick, H.B. and R.E. Pelletier, Response to soil moisture Spectral Indexes Derived from Bidirectional Reflectance in Thematic Mapper Wavebands. Remote Sensing of Environment, 25, pp. 167-184, 1988.

[7] Elmore, A.J., J.F. Mustard, and S.J. Manning, Regional Patterns of Plant Community Response to Changes in Water: Owens Valley, California. Ecological Applications, 13 (2), pp. 443-460, 2003.

[8] United States Geological Survey (USGS), EarthExplorer Online. http://earthexplorer.usgs.gov/

[9] National Aeronautics and Space Administration (NASA). Landsat Science Thematic Mapper. http://landsat.gsfc.nasa.gov/about/tm.html

[10] PRISM Climate Group, http://www.prism.oregonstate.edu/

[11] Gond, V., D.G. De Pury, F. Veroustraete, and R. Cuelemans, Seasonal variation in leaf area index, leaf chlorophyll and water content; scaling up to estimate fAPAR and carbon balance in a multilayer, multispecies temperate forest, Tree Physiology, 19, pp. 673-679, 1999.

[12] Schueler, C.F., and V.V. Salomonson, Landsat Image Data Quality Studies. Advances in Space Research, 5 (5), pp. 1-11, 1985.

[13] Chavez, P.S., Image-Based Atmospheric Corrections - Revisited and Improved. Photogrammetric Engineering and Remote Sensing, 62 (9), pp. 1025-1036, 1996.

[14] Chander, G. and B. Markham, Revised Landsat-5 TM Radiometric Calibration Procedures and Postcalibration Dynamic Ranges. IEEE Transactions on Geoscience and Remote Sensing, 41 (11), pp. 2674-2677, 2003.

[15] De Beurs, K.M. and G.M. Henebry, A statistical framework for the analysis of long image time series. International Journal of Remote Sensing, 26 (8), pp. 1551-1573, 2005.

[16] Vicente-Serrano, S.M., F. Perez-Cabello, and T. Lasanta, Assessment of radiometric correction techniques in analyzing vegetation variability and change using time series of Landsat imagery. Remote Sensing of Environment, 112, pp. 3916-3934, 2008.

[17] Chander, G., B.L. Markham, and D.L. Helder, Summary of current radiometric calibration coefficients for Landsat MSS, TM, ETM+, and EO1 ALI sensors. Remote Sensing of Environment, 113, pp. 893-903, 2009.

[18] Todd, S.W. and R.M. Hoffer, Responses of Spectral Indices to Variations in Vegetation Cover and Soil Background. Photogrammetric Engineering \& Remote Sensing, 64 (9), pp. 915-921, 1998. 